\title{
Review of intracorporeal and extracorporeal continent urinary diversion - where do we stand in 2021?
}

\author{
Felicia L. Balzano, Kevin G. Chan \\ Department of Surgery, City of Hope National Medical Center, Duarte, CA 91010, USA. \\ Correspondence to: Dr. Kevin G. Chan, Department of Surgery, City of Hope National Medical Center, 1500 E. Duarte Rd, \\ Duarte, CA 91010, USA. E-mail: kchan@coh.org
}

How to cite this article: Balzano FL, Chan KG. Review of intracorporeal and extracorporeal continent urinary diversion - where do we stand in 2021? Mini-invasive Surg 2021;5:41. https://dx.doi.org/10.20517/2574-1225.2021.49

Received: 5 Apr 2021 First Decision: 25 May 2021 Revised: 28 May 2021 Accepted: 7 Jun 2021 First online: 9 Jun 2021

Academic Editors: Giulio Belli, Riccardo Autorino, Richard Lawrence John Naspro Copy Editor: Xi-Jun Chen Production Editor: Xi-Jun Chen

\begin{abstract}
Robot-assisted radical cystectomy has become widely accepted as a safe and minimally invasive procedure for the treatment of bladder cancer. The urinary diversion continues to be performed completely intracorporeally or extracorporeally. Over the past decade, there has been an increasing number of continent diversions being performed intracorporeally. We evaluated the most recent literature regarding intraoperative metrics and outcomes that compare the intracorporeal and extracorporeal approaches.
\end{abstract}

Keywords: Cystectomy, intracorporeal, extracorporeal, continent urinary diversion

\section{INTRODUCTION}

Robot-assisted radical cystectomy (RARC) has become widely accepted as a safe minimally invasive procedure with equivalent oncologic outcomes ${ }^{[1,2]}$. The RAZOR trial showed RARC to have similar progression-free survival to open radical cystectomy ${ }^{[3]}$. Urinary diversion has historically been performed exclusively as an extracorporeal procedure, however, was first described using an intracorporeal technique in 2003 with the ileal conduit ${ }^{[4]}$. Since then, it has gained increasing popularity with recent data showing up to $97 \%$ of diversions being performed intracorporeally within some group ${ }^{[5]}$. We aim to discuss the current 
status of intracorporeal and extracorporeal continent urinary diversion in the setting of RARC. We evaluate the most contemporary data examining operative and postoperative metrics used to assess intracorporeal and extracorporeal approaches to continent diversions.

\section{EXTRACORPOREAL DEFINITION}

The definition of an extracorporeal diversion varies among surgeons. For many, this means making a laparotomy incision and performing the entirety of the procedure open. For others, a more hybrid approach is used that involves making a much smaller $5-7 \mathrm{~cm}$ incision and utilizing the robot to perform the urethral and/or ureteral anastomoses. This difference cannot be under-emphasized, as the hybrid approach allows for the possibility of less ureteral mobilization as well as a more precise urethral anastomosis for the orthotopic diversions. While the literature does not readily differentiate between the two, we will herein assume they are all the same for the purpose of this discussion.

\section{LEARNING CURVE}

The learning curve associated with intracorporeal continent urinary diversion should not be understated. There have been estimations of the learning curve for RARC and the agreement of 21-30 cases for this specific procedure has been reached to accomplish a lymph node yield of 20 as well as a positive surgical margin rate of $5 \%$ or lower ${ }^{[6]}$. While this may not seem like a large number of cases, "high volume centers" are 4-6 cases per year while "very high volume" centers are $7+\mathrm{RARC} / \mathrm{year}{ }^{[7]}$. This means that for a surgeon transitioning to intracorporeal diversions, it could take many years to cover the 30 cases required for the extirpative portion of the surgery alone.

Some groups have attempted to overcome this by having a clear mentor and mentee set-up with a set number of cases required to be performed together before operating independently ${ }^{[8]}$. In addition to this, some also have a group of nurses and technicians that exclusively work robotic cases and are present for all their diversion cases. While this would indeed aid with the learning curve, this is not feasible in all institutions.

\section{OPERATIVE TIME}

As we continue to move forward in the robotic era, the ever-pressing question continues to arise, "why should we continue to perform extracorporeal diversions over intracorporeal?" One of the big arguments is shorter operative times. Operative times from experienced surgeons range from 265-760 $\mathrm{min}^{[9]}$ for intracorporeal neobladders, while extracorporeal are $285-401^{[10,11]}$. Even in the most experienced hands, $58 \%-64 \%$ of patients experience a complication within the first 90 days after radical cystectomy regardless of how the diversion is performed ${ }^{[12,13]}$.

Zhang et al. ${ }^{[14]}$ recently published their data of 948 patients with 26 months of follow-up looking at intracorporeal diversions $v s$. RARC and open diversion $v s$. open radical cystectomy with open diversion. They found that the open radical cystectomy with open diversion had the shortest operative time. This intuitively makes sense and continues to be a motivating factor towards open diversions to attempt to minimize the operative time of an already long procedure. Novara et al.$^{[13]}$ found similar outcomes with shorter operative times associated with the open cystectomy. Shim et al. ${ }^{[15]}$ looked specifically at intracorporeal diversions compared to extracorporeal and found the operative time to also be significantly longer with the intracorporeal urinary diversion. Lenfant $e t$ al. ${ }^{[10]}$ also found that surgeons were less likely to offer a patient with an ASA score $\geq 3$ an intracorporeal urinary diversion given the potentially longer exposure to Trendelenburg position with pneumoperitoneum. This difference cannot be ignored when comparing these two surgical approaches and must remain a continued part of the conversation. 
In addition to longer operative times, performing extracorporeal diversions allows the surgeon to keep all diversion options available to patients. For example, if a surgeon is most comfortable with only the intracorporeal ileal conduit, they may be reticent to discuss a continent diversion option, orthotopic or cutaneous. This is critically important when discussing open and robotic diversions. Given the steep learning curve of robotic diversions, it is not unreasonable to think that many surgeons are prone to perform the procedure they are more comfortable and adept at rather than what may be best for the patient.

\section{COMPLICATIONS}

\section{Ureteroenteric stricture formation}

Stricture formation at the site of the anastomosis from the ureter to the bowel is a potentially catastrophic complication. These patients frequently require surgical intervention including invasive anastomotic revisions. Rates of ureteroenteric anastomotic stricture (UEAS) are reported to occur in $2.6 \%-13 \%$ of cases depending on the definition used ${ }^{[16]}$. Goh et al.$^{[17]}$ evaluated stricture formation between RARC and open radical cystectomy. They found that there was a higher stricture rate in the RARC group, however, this also related to the hospital volume, yet again emphasizing the steepness of the learning curve associated with these procedures. Of note, $84 \%$ of their diversions were incontinent diversions that were all performed extracorporeally.

Ericson et al. ${ }^{[16]}$ evaluated UEAS rates in open radical cystectomy, RARC with extracorporeal diversion, and RARC with intracorporeal diversion. Their cohort of an impressive 968 patients reported an overall 11.3\% stricture rate. Their subsets were broken down to a $9 \%, 11.3 \%$, and $13 \%$ rate for open, extracorporeal, and intracorporeal respectively with a statistically significant difference. What must be noted, however, is that the intracorporeal rate decreased from $17.5 \%$ to $4.9 \%$ after 75 cases; which again emphasizes the steep and long learning curve associated with these procedures. Also important to note in this cohort is that only $13 \%$ of their diversions were continent for the intracorporeal subset compared to $27 \%$ of their extracorporeal subset.

Ahmadi et al. ${ }^{[18]}$ looked at UEAS rates in intracorporeal diversions with and without the use of indocyanine green (ICG) for perfusion evaluation of the distal ureter. What they found was that not only was there a much greater amount of distal ureter excised before anastomosis ( $>5 \mathrm{~cm}$ in some cases) but that the ICG group had a $0 \%$ stricture formation at 12 months of follow up compared to the $10.6 \%$ per patient rate in the non-ICG group. Shen et al.$^{[19]}$ evaluated the stricture rate with extracorporeal diversions utilizing ICG with SPY fluorescence to evaluate for distal perfusion. They found the stricture rate again to be $0 \%$ in the ICG group vs. $7.5 \%$ in the non-ICG group. They also reported a longer excision of the distal ureter as well with $3.8 \mathrm{~cm}$ in the ICG group vs. $2.2 \mathrm{~cm}$ in the non-ICG group. These studies lead us to believe that perhaps the rate of UEAS is not dependent on the method of diversion creation, but rather distal ureteral perfusion ${ }^{[19]}$.

\section{Gastrointestinal complications}

Gastrointestinal complications continue to be a major cause of morbidity in the cystectomy patient. Patient's hospital stays are prolonged with ileus, jaundice, and hematochezia as well as readmissions for similar issues. Shim et al. ${ }^{[15]}$ looked at complications between intracorporeal urinary diversion and extracorporeal urinary diversion in 362 patients. They found that gastrointestinal complications were significantly higher in the extracorporeal urinary diversion group. Zhang et al. ${ }^{[14]}$ also found a significantly lower gastrointestinal complication rate with the intracorporeal urinary diversion compared to both the extracorporeal urinary diversion and the open cystectomy. They found that the TPN requirement was highest for open cases. Hussein et al. ${ }^{[5]}$, however, found no significant difference in gastrointestinal complications between the intracorporeal urinary diversion and extracorporeal urinary diversion group, 
looking at 972 patients. Feng et al. ${ }^{[20]}$ found fewer gastrointestinal complications with intracorporeal urinary diversions with $60 \%$ being continent diversions. Ahmed et al. ${ }^{[21]}$ found that $10 \%$ of intracorporeal diversions had gastrointestinal complications compared to $23 \%$ of those who underwent extracorporeal diversion.

The lower gastrointestinal complication rates associated with intracorporeal diversions are thought to be due to less bowel manipulation, exposure and mobilization ${ }^{[21]}$. Shim et al. ${ }^{[15]}$ defined gastrointestinal complications to include ileus, jaundice and hematochezia. Zhang et al. ${ }^{[14]}$ by contrast defined gastrointestinal complications as ileus, diarrhea, gastrointestinal bleeding, gastritis and/or Clostridium difficile. These subtle differences in inclusion criteria and definitions of what constitutes a gastrointestinal complication may begin to explain why these results are inconsistent across so many different studies.

\section{POSTOPERATIVE PARAMETERS}

Postoperative parameters including length of stay, infections, and overall complications are consistent metrics evaluated when discussing the benefits of robotic surgery. With ERAS protocols integrated into most systems now, the time to discharge has significantly decreased after large abdominal procedures including radical cystectomy ${ }^{[22]}$. Hussein et al..$^{[5]}$ evaluated intracorporeal $v s$. extracorporeal diversion after RARC outcome parameters in 972 patients and found that the intracorporeal diversion had more complications and readmissions, however, these were not high-grade complications. They also noted that that there were more infectious complications associated with the intracorporeal diversions. There was also a 1 day longer admission with the intracorporeal diversion subset.

Shim et al. ${ }^{[15]}$ also examined the outcomes of intracorporeal urinary diversion $v s$. extracorporeal urinary diversion. They found that the intracorporeal urinary diversion group had significantly shorter recovery parameters including time to passage of flatus, the start of oral intake, and length of hospital stay. Mazzone et al. ${ }^{[23]}$ did not find any difference in length of stay between intracorporeal urinary diversion and extracorporeal urinary diversion. Lenfant et al. ${ }^{[10]}$ also found that there was no difference in length of stay between the two groups. The data regarding length of hospital stay remains highly variable and inconclusive. Tables 1 and 2 show intraoperative and post-operative parameters between intracorporeal and extracorporeal urinary diversions.

\section{FUNCTIONAL OUTCOMES}

There continues to be limited data on functional outcomes for intracorporeal urinary diversion. Functional outcomes are influenced by many factors including patient age, mental status, reservoir volume, and urethral length. Tyritzis et al. ${ }^{[9]}$ had a cohort of 70 patients with an $88 \%$ daytime continence rate with an orthotopic Studer neobladder performed intracorporeally. Of this group, 88.6\% were men. At their one-year follow-up, 46 men and 2 out of 3 females were defined as the continent with $<1$ pad per day. One of the females had hypercontinence requiring clean intermittent catheterization. Canda et al.$^{[29]}$ reported daytime continence in 11 out of 17 patients who underwent intracorporeal urinary diversion with an orthotopic neobladder.

Obrecht et al. ${ }^{[24]}$ recently published their one-year data of intracorporeal orthotopic neobladder creation looking primarily at functional outcomes. They had a 100\% "social continence" rate, defined as $<1$ pad per day as well as post-void residual of 0 with a median pouch capacity of $404 \mathrm{cc}^{[24]}$. It is important to note, however, that this is a small sample of 12 patients that were all male. It is difficult to be able to extrapolate this data over larger, more diverse populations. In addition to this, continence definitions vary widely across studies with terms such as "daytime continence" and "social continence" sometimes being used interchangeably without having a consistent clear definition. 
Table 1. Robotic radical cystectomy with intracorporeal urinary diversion operative and post-operative characteristics

\begin{tabular}{|c|c|c|c|c|c|c|c|c|}
\hline Study & $\mathbf{N}$ & $\begin{array}{l}\text { Length of surgery (min) } \\
\text { (median/mean) }\end{array}$ & $\begin{array}{l}\text { Length of stay } \\
\text { (mean/median days) }\end{array}$ & $\begin{array}{l}\text { Complication rate } \\
\text { Clavien } 1-290 \mathrm{~d} / 30 \mathrm{~d} \\
\text { (\%) }\end{array}$ & $\begin{array}{l}\text { Complication rate } \\
\text { Clavien 3-5 90d/30d } \\
\text { (\%) }\end{array}$ & $\begin{array}{l}\text { GI } \\
\text { complications } \\
(\%)\end{array}$ & $\begin{array}{l}\text { Overall complication } \\
\text { rate } 90 \mathrm{~d} / 30 \mathrm{~d}(\%)\end{array}$ & $\begin{array}{l}\text { Continence (0-1 } \\
\text { pad/d) (day \%/night } \\
\%)\end{array}$ \\
\hline $\begin{array}{l}\text { Hussein et al. }{ }^{[11]} \\
2020\end{array}$ & 486 & $355 /-$ & -19 & - & $14 / 12$ & 23 & $52 / 47$ & - \\
\hline $\begin{array}{l}\text { Mazzone et al. }{ }^{[23]} \\
2021\end{array}$ & 162 & $350 /-$ & $-/ 11.5$ & - & $-/ 35.2$ & - & - & - \\
\hline $\begin{array}{l}\text { Lenfant et al. }{ }^{[10]} \\
2018\end{array}$ & 74 & $320 /-$ & $-/ 14$ & $6.7 / 38$ & $12.2 / 9.5$ & - & $18.9 / 47.3$ & - \\
\hline $\begin{array}{l}\text { Zhang et al. }{ }^{[14]} \\
2020\end{array}$ & 301 & $390 /-$ & $6 /-$ & - & $16.9 / 10$ & 23.3 & $44.2 / 37.5$ & - \\
\hline $\begin{array}{l}\text { Shim et al. }{ }^{[15]} \\
2020\end{array}$ & 84 & $-/ 566$ & 16.6/- & $26.7 /-$ & 14.7 & 4.8 & $41.7 /-$ & - \\
\hline $\begin{array}{l}\text { Obrecht et al. } .^{[24]} \\
2020\end{array}$ & 12 & $575 /-$ & - & - & - & - & - & $100 / 75$ \\
\hline $\begin{array}{l}\text { Tyritzis et al. } \\
2013\end{array}$ & 70 & $420 /-$ & $-/ 9$ & $17 /-$ & $37.1 /-$ & 21.4 & $51.2 / 48.4$ & $68.5 / 57.4$ \\
\hline $\begin{array}{l}\text { Mistretta et al. }{ }^{[25]} \\
2021\end{array}$ & 57 & - & - & - & - & - & - & $89.4 / 87.1$ \\
\hline $\begin{array}{l}\text { Balbay et al. }{ }^{[26]} \\
2020\end{array}$ & 22 & $-/ 552$ & $10.5 /-$ & $13.6 / 92$ & $18.2 / 9$ & 13.6 & - & $82.3 / 47.1$ \\
\hline $\begin{array}{l}\text { Tuderti et al. }{ }^{[27]} \\
2020\end{array}$ & 167 & $420 /-$ & - & - & - & - & - & $70-90$ \\
\hline
\end{tabular}

Grimm et al.$^{[30]}$, by contrast to the intracorporeal orthotopic neobladder, had 178 patients who underwent creation of orthotopic neobladder in an extracorporeal manner with $48.5 \%$ daytime continence and $34.9 \%$ nighttime continence. This group, however, does not specify which of these patients underwent RARC as opposed to open radical cystectomy ${ }^{[30]}$. Mistretta et al. ${ }^{[25]}$ also compared continence rates of RARC with intracorporeal and extracorporeal orthotopic neobladders with no statistically significant difference in functional outcomes [Tables 1 and 2]. Lin et al. ${ }^{[28]}$ use a hybrid approach by performing a RARC, extracorporeal creation of the neobladder, and laparoscopic urethra-neobladder anastomosis with $90 \%$ daytime and $82 \%$ nighttime continence [Table 2]. Despite this, there is a paucity of data on the functional outcomes for extracorporeal urinary diversion after RARC, however, daytime rates in the larger open studies range from 54\%-99\% daytime continence $36 \%-84.6 \%$ nighttime continence ${ }^{[12,31-35]}$.

\section{Limitations}

Overall experience with intracorporeal and extracorporeal urinary diversion has grown immensely over the past 20 years. This report presents the most recent and robust studies to address the important questions to consider when deciding between the two techniques. While we can make see emerging themes within 
Table 2. Robotic radical cystectomy with extracorporeal urinary diversion operative and post-operative characteristics

\begin{tabular}{|c|c|c|c|c|c|c|c|c|}
\hline Study & $\mathbf{N}$ & $\begin{array}{l}\text { Length of surgery (min) } \\
\text { (median/mean) }\end{array}$ & $\begin{array}{l}\text { Length of stay } \\
\text { (mean/median days) }\end{array}$ & $\begin{array}{l}\text { Complication rate } \\
\text { Clavien } 1-290 \mathrm{~d} / 30 \mathrm{~d} \\
\text { (\%) }\end{array}$ & $\begin{array}{l}\text { Complication rate } \\
\text { Clavien 3-5 90d/30d } \\
\text { (\%) }\end{array}$ & $\begin{array}{l}\text { GI } \\
\text { complications } \\
(\%)\end{array}$ & $\begin{array}{l}\text { Overall complication } \\
\text { rate } 90 \mathrm{~d} / 30 \mathrm{~d}(\%)\end{array}$ & $\begin{array}{l}\text { Continence (0-1 } \\
\text { pad/d) (day \%/night } \\
\%)\end{array}$ \\
\hline $\begin{array}{l}\text { Hussein et al. }{ }^{[5]} \\
2018\end{array}$ & 486 & $401 /-$ & $-/ 8$ & - & $12 / 10$ & 20 & $35 / 28$ & - \\
\hline $\begin{array}{l}\text { Mazzone et al. }{ }^{[23]} \\
2021\end{array}$ & 105 & $350 /-$ & $-/ 13$ & - & $-/ 42.9$ & - & - & - \\
\hline $\begin{array}{l}\text { Lenfant et al. }{ }^{[10]} \\
2018\end{array}$ & 34 & $285 /-$ & $-/ 12$ & $11.7 / 32.4$ & $17.6 / 5.9$ & - & $29.4 / 38.2$ & - \\
\hline $\begin{array}{l}\text { Zhang et al. }{ }^{[14]} \\
2020\end{array}$ & 375 & $421 /-$ & $7 /-$ & - & $24.8 / 17.9$ & 29.3 & $48.3 / 43.2$ & - \\
\hline $\begin{array}{l}\text { Shim et al. }{ }^{[15]} \\
2020\end{array}$ & 278 & $-/ 510$ & $22.4 /-$ & $41 /-$ & $20.5 /-$ & 12.9 & $61.5 /-$ & - \\
\hline $\begin{array}{l}\text { Mistretta et al. }{ }^{[25]} \\
2021\end{array}$ & 44 & - & - & - & - & - & - & $63.8 / 51.6$ \\
\hline Lin et al. ${ }^{[28]} 2008$ & 108 & $-/ 330$ & - & - & - & - & 18.5 & $90.7 / 82.6$ \\
\hline
\end{tabular}

this growing body of evidence, the paucity of level one evidence limits our ability to draw definitive conclusions.

\section{CONCLUSIONS}

RARC has taken over as the treatment of choice in most cases in the treatment of muscle-invasive bladder cancer. As intracorporeal urinary diversion continues to gain popularity, we need to continue to challenge the data and evaluate if we are making the right decision for our patients. After looking across the data provided worldwide, there continues to be a reason to pause with the sweeping adoption of the intracorporeal urinary diversion with continued varied data of the superiority of outcomes.

\section{DECLARATIONS}

Authors' contributions

Balzano FL and Chan KG contributed equally to all components of the manuscript.

\section{Availability of data and materials}

Not applicable. 


\section{Financial support and sponsorship}

None.

\section{Conflicts of interest}

Both authors declare that there are no conflicts of interest.

\section{Ethical approval and consent to participate}

Not applicable.

\section{Consent for publication}

Not applicable.

\section{Copyright}

(c) The Author(s) 2021.

\section{REFERENCES}

1. Menon M, Hemal AK, Tewari A, et al. Nerve-sparing robot-assisted radical cystoprostatectomy and urinary diversion. BJU Int 2003;92:232-6. DOI PubMed

2. Gandaglia G, De Groote R, Geurts N, et al. Oncologic outcomes of robot-assisted radical cystectomy: results of a high-volume robotic center. J Endourol 2016;30:75-82. DOI PubMed

3. Parekh DJ, Reis IM, Castle EP, et al. Robot-assisted radical cystectomy versus open radical cystectomy in patients with bladder cancer (RAZOR): an open-label, randomised, phase 3, non-inferiority trial. Lancet 2018;391:2525-36. DOI PubMed

4. Beecken W, Wolfram M, Engl T, et al. Robotic-assisted laparoscopic radical cystectomy and intra-abdominal formation of an orthotopic ileal neobladder. Eur Urol 2003;44:337-9. DOI PubMed

5. Hussein AA, May PR, Jing Z, et al; Collaborators. Outcomes of intracorporeal urinary diversion after robot-assisted radical cystectomy: results from the international robotic cystectomy consortium. J Urol 2018;199:1302-11. DOI PubMed

6. Hayn MH, Hussain A, Mansour AM, et al. The learning curve of robot-assisted radical cystectomy: results from the International Robotic Cystectomy Consortium. Eur Urol 2010;58:197-202. DOI PubMed

7. Leow JJ, Reese S, Trinh QD, et al. Impact of surgeon volume on the morbidity and costs of radical cystectomy in the USA: a contemporary population-based analysis. BJU Int 2015;115:713-21. DOI PubMed

8. Murthy PB, Bryk DJ, Lee BH, Haber GP. Robotic radical cystectomy with intracorporeal urinary diversion: beyond the initial experience. Transl Androl Urol 2020;9:942-8. DOI PubMed PMC

9. Tyritzis SI, Hosseini A, Collins J, et al. Oncologic, functional, and complications outcomes of robot-assisted radical cystectomy with totally intracorporeal neobladder diversion. Eur Urol 2013;64:734-41. DOI PubMed

10. Lenfant L, Verhoest G, Campi R, et al. Perioperative outcomes and complications of intracorporeal vs extracorporeal urinary diversion after robot-assisted radical cystectomy for bladder cancer: a real-life, multi-institutional french study. World J Urol 2018;36:1711-8. DOI PubMed

11. Hussein AA, Elsayed AS, Aldhaam NA, et al. A comparative propensity score-matched analysis of perioperative outcomes of intracorporeal vs extracorporeal urinary diversion after robot-assisted radical cystectomy: results from the International Robotic Cystectomy Consortium. BJU Int 2020;126:265-72. DOI PubMed

12. Hautmann RE, Abol-Enein H, Davidsson T, et al; International Consultation on Urologic Disease-European Association of Urology Consultation on Bladder Cancer 2012. ICUD-EAU International Consultation on bladder cancer 2012: urinary diversion. Eur Urol 2013;63:67-80. DOI PubMed

13. Novara G, Catto JW, Wilson T, et al. Systematic review and cumulative analysis of perioperative outcomes and complications after robot-assisted radical cystectomy. Eur Urol 2015;67:376-401. DOI PubMed

14. Zhang JH, Ericson KJ, Thomas LJ, et al. Large single institution comparison of perioperative outcomes and complications of open radical cystectomy, intracorporeal robot-assisted radical cystectomy and robotic extracorporeal approach. J Urol 2020;203:512-21. DOI PubMed

15. Shim JS, Kwon TG, Rha KH, et al. Do patients benefit from total intracorporeal robotic radical cystectomy? Investig Clin Urol 2020;61:11-8. DOI PubMed PMC

16. Ericson KJ, Thomas LJ, Zhang JH, et al. Uretero-enteric anastomotic stricture following radical cystectomy: a comparison of open, robotic extracorporeal, and robotic intracorporeal approaches. Urology 2020;144:130-5. DOI PubMed

17. Goh AC, Belarmino A, Patel NA, et al. A population-based study of ureteroenteric strictures after open and robot-assisted radical cystectomy. Urology 2020;135:57-65. DOI PubMed

18. Ahmadi N, Ashrafi AN, Hartman N, et al. Use of indocyanine green to minimise uretero-enteric strictures after robotic radical cystectomy. BJU Int 2019;124:302-7. DOI PubMed

19. Shen JK, Jamnagerwalla J, Yuh BE, et al. Real-time indocyanine green angiography with the SPY fluorescence imaging platform decreases benign ureteroenteric strictures in urinary diversions performed during radical cystectomy. Ther Adv Urol 
2019;11:1756287219839631. DOI PubMed PMC

20. Feng D, Tang Y, Yang Y, Han P, Wei W. Intracorporeal versus extracorporeal urinary diversion after robotic-assisted radical cystectomy: evidence from a systematic review and pooled analysis of observational studies. Minerva Urol Nefrol 2020;72:519-30. DOI PubMed

21. Ahmed K, Khan SA, Hayn MH, et al. Analysis of intracorporeal compared with extracorporeal urinary diversion after robot-assisted radical cystectomy: results from the International Robotic Cystectomy Consortium. Eur Urol 2014;65:340-7. DOI PubMed

22. Semerjian A, Milbar N, Kates M, et al. Hospital charges and length of stay following radical cystectomy in the enhanced recovery after surgery era. Urology 2018;111:86-91. DOI PubMed

23. Mazzone E, D'Hondt F, Beato S, et al. Robot-assisted radical cystectomy with intracorporeal urinary diversion decreases postoperative complications only in highly comorbid patients: findings that rely on a standardized methodology recommended by the European Association of Urology Guidelines. World J Urol 2021;39:803-12. DOI PubMed

24. Obrecht F, Youssef NA, Burkhardt O, et al. Robot-assisted radical cystectomy and intracorporeal orthotopic neobladder: 1-year functional outcomes. Asian J Androl 2020;22:145-8. DOI PubMed PMC

25. Mistretta FA, Musi G, Collà Ruvolo C, et al. Robot-assisted radical cystectomy for nonmetastatic urothelial carcinoma of urinary bladder: a comparison between intracorporeal versus extracorporeal orthotopic ileal neobladder. $J$ Endourol 2021;35:151-8. DOI PubMed

26. Balbay MD, Canda AE, Kiremit MC, Koseoglu E. Intracorporeal Studer Pouch Formation with Balbay's Technique following robotic radical cystectomy for bladder cancer: experience with 22 cases with oncologic and functional outcomes. $J$ Endourol 2020;34:273-80. DOI PubMed

27. Tuderti G, Mastroianni R, Brassetti A, et al. Robot-assisted radical cystectomy with intracorporeal neobladder: impact of learning curve and long-term assessment of functional outcomes. Minerva Urol Nefrol 2020. DOI PubMed

28. Lin TX, Huang J, Xu KW, et al. Laparoscopic radical cystectomy with orthotopic ileal neobladder: report of 108 cases. Zhonghua Yi Xue Za Zhi 2008;88:2437-40. PubMed

29. Canda AE, Atmaca AF, Altinova S, Akbulut Z, Balbay MD. Robot-assisted nerve-sparing radical cystectomy with bilateral extended pelvic lymph node dissection (PLND) and intracorporeal urinary diversion for bladder cancer: initial experience in 27 cases. BJU Int 2012;110:434-44. DOI PubMed

30. Grimm T, Grimm J, Buchner A, et al. Health-related quality of life after radical cystectomy and ileal orthotopic neobladder: effect of detailed continence outcomes. World J Urol 2019;37:2385-92. DOI PubMed

31. De Sutter T, Akand M, Albersen M, et al. The N-shaped orthotopic ileal neobladder: functional outcomes and complication rates in 119 patients. Springerplus 2016;5:646. DOI PubMed PMC

32. Kretschmer A, Grimm T, Buchner A, et al. Prognostic features for objectively defined urinary continence after radical cystectomy and ileal orthotopic neobladder in a contemporary cohort. J Urol 2017;197:210-5. DOI PubMed

33. Meyer JP, Drake B, Boorer J, Gillatt D, Persad R, Fawcett D. A three-centre experience of orthotopic neobladder reconstruction after radical cystectomy: initial results. BJU Int 2004;94:1317-21. DOI PubMed

34. Muto G, Collura D, Simone G, et al. Stapled orthotopic ileal neobladder after radical cystectomy for bladder cancer: functional results and complications over a 20-year period. Eur J Surg Oncol 2016;42:412-8. DOI PubMed

35. Hautmann RE, Volkmer B, Egghart G, et al. Functional outcome and complications following ileal neobladder reconstruction in male patients without tumor recurrence. More than 35 years of experience from a single center. J Urol 2021;205:174-82. DOI PubMed 